\title{
Globalization and the Fallacy of Technology Learning: Rethinking the Technology Transfer Argument
}

\author{
Dr. Uwem Essia \\ Department of Economics University of Calabar Calabar, Nigeria
}

\begin{abstract}
Revolutions in ICT and the internationalization of industrial and services technologies associated with globalization have generally supported the thinking that technology learning and imitation have become easier for today's poor countries. This paper agrees that globalization has eased access to new knowledge, but the tacitness of new technologies has made it increasingly easier for high-tech firms to hoard vital information on innovations, and restrict the flow of new technologies to firms in poor countries. Accordingly, firms and governments in poor countries should not take the neoclassical economic technology transfer view for granted Poor countries desiring speedy technological progress need to invest deliberately in technology learning, and adaptation of innovations to meet local needs.
\end{abstract}

Key Words: Information Technology, Globalization, Multinational Corporations, Tacit Knowledge, Internet.

\section{Technology Transfer And Convergence}

The Internet explosion has eased the spread of new knowledge and information, making it easier and cheaper for new technologies and inventions to diffuse from the technologically advanced countries to poor countries. The possibility that technological innovations will spill over to poorer societies has increased. Accordingly, neoclassical economics predict that the growth rates of different countries should converge in the long run. The underlying assumption of this convergence thesis is diminishing marginal product of capital in the innovating country/region: as capital stock increase and become excessive in the innovating country/region, diminishing returns will set in and the marginal productivity of capital will fall; making it more gainful to move capital from the advanced economies to poorer countries, where capital is scarce and returns on capital are much higher. The extant neoclassical economic literature, therefore, links technology transfer to capital movement, and focuses principally on the aspect of technical change that is embodied in capital stock.

In the neoclassical economic tradition therefore, technology transfer is taken for granted as long as capital movement takes place. Technology transfer is considered an essential component of the normal on-going evolutionary growth processes that will ordinarily take place as long as there is exchange. However economic theory does not conclusively explain why and how the on-going evolutionary growth processes will take place, or why some countries have advanced faster than others, and why convergence will ultimately occur. Rather it is predicted that; "there is a natural tendency for production per head of different countries to converge mainly because technology is universally available" (Ploeg, 1994:552).

But if "technology is universally available" why is there a growing divide between rich and poor countries. Why is it that since after World War II, when modern development studies commenced, no poor country has become rich by applying the neoclassical economic doctrine. Rather, aside from the so-called 'Asian tigers' who deliberately fought their way to prosperity, the entire developing world has remained a 'development desert'. Indeed, the presumption that "technology is universally available" has no proof in the neoclassical economic theory. Early economists' generally associated technological change with capital accumulation, and like labour capital was assumed to be a variable factor that is freely available and mobile, hence the presumption that technological changes and scientific discoveries will diffuse speedily and that no nation can expect to keep new inventions secret for any length of time

Closely related to the technology diffusion view, is the presumption that it is much easier and cheaper for poorer countries to benefit from technology spillovers, than to engage in the process of generating new technologies. This is because the cost of adapting existing technologies is considered far less than attempting to discover or invent new knowledge, and countries that borrow technology, or benefit from technological transfer from abroad should have a much easier task than the countries in which the technological change had originally occurred. The technology transfer arguments support the view that late starters might overtake the original inventing countries.

The thinking that late starters might overtake the original inventing countries is the very essence of the so-called technology-gap theory of trade (Bloomfield, 1978:612). The technology gap theory predicts that latecomers can improve on the initial innovation and possibly overtake the original innovating countries. It is assumed however that the original innovating countries would slow down innovations, and do nothing to check 
the flow of new technologies to the latecomers. But this has been found not to be the case, as many innovating countries have remained on the tip-top of technological development, and the flow of knowledge to imitating countries is generally restricted. This is particularly so as commitment to on-going technological development in several imitating countries has remained weak. Moreover, there is growing comparative advantage in advanced economies trading among themselves. One cannot agree less with Ploeg (1994) that the empirical speed of convergence is much slower than neoclassical economic theory predicts.

\section{The Fallacy Of Diminishing Returns To Technological Innovations}

The thinking that average returns on capital will reduce in the innovating country is central to the technology transfer view. Capital owners seeking higher returns will move capital assets to the imitating countries, and imitation is ensured as the imported capital assets (presumably with embodied technology) are deployment along with indigenous labour for producing goods and services in imitating countries. Diffusion of information technology to the imitating countries is eased further by explosion in information technology. So, poor countries can take technology transfer for granted as long as there are minimal inhibitions to the flow of capital and labour from innovating countries. This chain of arguments was behind the failed Structural Adjustment Programmes (SAPs) promoted by the IMF and World Bank in the 1980s.

Bloomfield (1978:612) puts the technology transfer arguments thus:

A country develops a new export product, and a new process that lowers the cost of an existing export. A special advantage is thereby conferred on the innovating country and the volume of its export increases. But the advantage and the trade that it generates are gradually lost as the new technology is imitated or otherwise diffused abroad. Indeed, if foreign countries have relative factor endowments and factor prices that make them more suitable producers of the commodity in question, ...or if they improve upon the initial innovation... they could successfully compete in the commodity concerned in their markets or even begin exporting it back to the innovating country itself.

Whether the marginal product of capital will rise or fall in the innovating countries has little or nothing to do with disembodied technology, and in a growing cultural economy as it is the case now new technologies come more as technical knowledge and skills or more generally human capital assets, rather than embodied capital as was the case in the industrial economy of classical and neoclassical economics. The new knowledge societies associated with today's realities has separated the trajectories of capital (a stock) and knowledge and skills (a flow). It has become possible and very easy to ship capital assets into poor countries without any form of technological transfer, in much the same way as it is possible to achieve technological sophistication without capital movement. When new technologies are reckoned as technological knowledge and technical skills, it becomes clear why competition will more likely lead to increasing productivity and returns to all production inputs, including capital.

Equally, in the new knowledge society, cultural resources have become very important and new forms of capital and labour have emerged, and differentiating the cultural aspects of labour and capital is increasingly difficult. The mindset is an example of non-material factor of production with both labour and capital elements. From the perspective of an individual, the mindset determines: ones divinity - relationship with God (nature or cosmos); ones attitude - relationship with others; and one's self image - how one sees his or herself. Divinity defines the scope of what one considers achievable and the driving force for determining how to attract from the cosmos. Attitude defines how the individual relates with others in the production process, while self-image determines what role the individual decides to play in the society.

A society where more people are attuned to the cosmos would have higher capability for attracting more development, sophistication, and generally improved ways of doing things, with minimal limitations. Equally, the right attitude facilitates production by reducing avoidable conflicts and ensuring that more people are engaged in productive endeavours, and for a society the closer the collective consciousness is attuned to the cosmos the faster is its development. This makes 'cultural capital', the collective consciousness of a society that defines the dominant mindset of the society the key spiritual infrastructure of modern development.

The mindset defines three major relationships, namely; how majority of people in a society see the universe, how individuals in the society see themselves in relation to others, and what people see as their roles. The dominant mindset determines how a group of people or society set out to progress materially. Development is therefore not simply the accumulation of material goods and services but more importantly the accumulation of cultural assets.

The thinking in conventional neoclassical economics that technology can be transferred through trade is based on the assumption that the innovating countries will do nothing to check the free flow of new technologies across its borders, and that there is free trade between the innovating and the imitating countries; such that both set of countries benefit mutually from new technologies and international trade. But in reality, innovating country gain by restricting the flow of new technologies to the imitating countries, and even if it was possible to transfer the technological skills and knowledge it would still be incomplete because the cultural capital (attitudes and mindsets) for driving technological change can hardly be transferred. The spiritual 
culturing of today's human development space has increasingly made it difficult to embody technological change in goods and services as conventional neoclassical economics would want us to think. Each society must strive to build and nurture its stock of cultural capital.

Moreover, in today's knowledge societies, "cultural advantage" rather than "factor endowment" defines comparative advantage, and technological change is increasingly a cultural artifact. Cultural advantage as embodied in entrepreneurial attitudes, mindset, and collective conscience endues the innovating countries with monopolistic rents, strategic global relevance, and invincibility that are over and about the conventional neoclassical economic Hecksher-Ohlin-Samuelson-Stolper resource allocation gains from international trade. In reality therefore technology is not universally available, recent revolutions in information technology and internationalization of finance has not ensured the universal availability of technical skills and technological knowledge.

\section{The Fallacy Of Convergence And Technology Transfer}

It follows from the above analysis that the on-going convergence of cultures that is associated with globalization is not synonymous with technology transfer (if technology is seen as an embodiment of the cultural capital or 'spirit of the society'). Therefore, today's poor countries that desire to join the club of fast moving economies need to look beyond importation of machines, foreign direct investment, and capital transfers generally. With the appropriate 'spirit of the society' a poor country can leapfrog from the primitive stage straight to technological sophistication without going through the transitional stages of the so called technologygap models. Clearly the appropriate 'spirit of the society' manifests itself in the right leadership, and there is a direct relationship between quality of leadership and appropriateness of the 'spirit of the society'.

Lessons from the experiences of today's fast moving economies, like United Arab Emirate (Dubai), India, Singapore, and China (to mention a few) indicate a strong chain between spirit of the society, leadership, and speedy socioeconomic transformation, and show clearly that it is possible for poor peasantry economies to leapfrog industrialization and proceed straight to technological sophistication. But the cultural dynamics of modern technology has made it increasingly impossible for imitating countries to experience technological transfer by relying explicitly on technological spillovers. This partially explains why since after World War II, when development economics became prominent, no known country has achieved significant development on the basis of the conventional neoclassical economic development logic.

Marginal productivity of capital has continued to rise in the innovating countries because of the limitless expansiveness of cultural capital, and the cultural backwardness of many poor countries makes them increasingly dependent on more mature knowledge societies, thereby weakening their capacity to innovate or chart independent courses of progress themselves in line with their cultural specificities and historical contexts. Moreover foreign direct investment from advanced economies to technology weak economies may lead to the reverse movement of financial and human capital to the advanced economies, instead of technology transfer, because the weak education system in most poor countries makes its population intellectually and culturally illprepared to learn, adopt, and adapt the transferable technical skills and competencies that are acquired through learning.

In essence therefore, technology-gap theories and indeed neoclassical economics generally cannot be relied upon for guiding poor countries to achieve technological advancement presently. Poor countries desiring technological progress need to see it in the context of leapfrogging industrialization, or taking the quantum leap from the limitedness of primitivism to the expansiveness technological sophistication. Development thinking needs to shift from the mere accumulation of material (money and machines) capital, to cultural capital formation and achieving the appropriate 'spirit of the society'.

\section{Globalization Of Trade And Technology Transfer}

Mahler (2002) rightly observes that globalization has tended to promote free trade, flow of FDI, mobility of labour, and other sources of technology spillovers that can raise the average income in poor countries. But the possible gains from globalization are largely negated by the problems of inequality, insecurity and injustice that characterize the flow of resources, exchange rates and earning across the different regions and within countries (see Toyo, 2001; Onimode, 2000; Garba, 2003), by virtue of its internal logics, incomes within the global capitalist system is inescapably prone to cyclical fluctuations. Exploitation and deprivation, and incomes grow as global trade is increasingly globalized, and convergence of access to information and financial systems cannot be seen to be going along with convergence of incomes and technologies; there is indeed the paradox of 'convergence of the financial system existing side by side with divergence of incomes', or 'poverty amidst riches'.

it must be noted also that globalization of trade has not necessarily translated to more trade between the advanced economies and less developed economies. Indeed the general thinking within communities of advanced economies has supported more trade between developed countries than developed countries with the less developed countries. International trade has grown at roughly double the rate of world GDP on the average 
since after World War II. But over 40 per cent of the volume of trade in manufacturing is intra-firm trade among the subsidiaries of multinational corporations (MNCs). The obvious implication of this is less growth in today's poor countries. Generally therefore, the search for more technological advantage by the advanced economies is associated with restriction in technology flows and trade to poor countries, and "the empirical speed of convergence is much slower than the neoclassical theory predicts" (Ploeg, 1994:552).

\section{Foreign Direct Investment And Technology Transfer}

FDI of multinational corporations (MNCs) now play an important role in growth of poor countries, and hence the current policy focus to most LDCs aims at attracting FDI. However, as Bhaduri (2000) rightly observes, the importance of FDI in global economic growth is often over estimated in the conventional development thought: the quantitative importance of FDI in terms of its share either in fixed capital formation, or the accumulate stocks of FDI as a share of GDP, is not overwhelmingly large. For all economics, its share in fixed capital formation roughly double from 4.4 to 8.7 per cent on a four-year average between 1981 and 1985 and 1991 and $1995 \ldots$ and as a ratio of GDP the accumulated FDI stock increase over the period from about 11 to 20 per cent.... Even for the more open industrializing economics, the figures are not very different, the former share was about 10.7 per cent in South East Asia and 10 per cent in Latin America in 1991-1995, but highest at 13.6 percent in Europe" (Bhaduri, 2000:22-23).

For sub-Sahara Africa (SSA) the ratio of GDP to accumulated FDI stock was 10 percent in 1999 (Onimode, 2000:91). Besides, capital movements are not necessary for the MNC's FDI. The MNC or its subsidiaries can source for funds in the host capital market without having to obtain outside funds. It is therefore incorrect to always associate MNC's FDI in poor countries with capital inflow. FDI may indeed cause net capital outflow if the rate of profit repatriation and payment for imported factor services are growing.

Apart from FDI and its role in facilitating capital movements, the MNC equally engages in licensing, out sourcing and joint ventures and these also extend their influence on global trade performance. Bhaduri (2000:23) elaborate this point further:(MNC) are involved increasingly in activities like licensing, outsourcing and joint ventures, including international marketing, which are not captured in the measures of FDI. They become important in influencing the trade performance of the nation-state through these channels, and in updating technologies in newly industrializing nations. Moreover, (MNC) are engaged increasingly not only in international production activities, but also in finance. It is often easier for a domestic firm in a developing country to raise commercial loans internationally through joint venture, and to obtain a better internationally approved credit rating, if it is linked to a well-known multinational.

Growth in FDI does not there guarantee technology transfer to poor countries.

\section{The Information Revolution And Technology Transfer}

Innovations in ICT technology and delivery systems have reduced the cost of disseminating information substantially. But, economists have paid little attention to the tremendous power of the electronic media in shaping and influencing sentiments that drive global development thought and policy advice. The received economic theories and hypotheses may not be important in shaping academic research, but the global media significantly shapes economic reasoning and the views of policy makers.

As Bhaduri (2000:26) rightly observes, the media is not necessarily involved in the business of formulating the theories and hypotheses around which the sentiments in the market crystallize, but it packages and markets them. For example, beliefs in the efficiency and wisdom of the market, and the inefficiencies of government ownership are sometime propagated by the media to become popular beliefs, and from finance ministers to the ordinary participants, and the general public, these beliefs become the "distilled truths" continuously served by the media. Those distilled truths, when they become sufficiently popular in a globally integrated financial market, force national governments to act according to them. This social process, enormously strengthened by the advances in communication technology, can make national governments unable or even unwilling to act with determination in the face of poverty, unemployment or environmental degradation, particularly when such real issues conflict with the particular theories propagated. Therefore, the tendency is for the Western media to propagate as received theories those beliefs that are especially convenient to powerful capitalist interests.

For example, it is widely believed that internationalization of finance has led to establishment of more firms, thereby inducing more competition among firms. But this popular view on the competitiveness of globalization is mere pedagogic rhetoric. The very large producers are often closely linked subsidiaries of the MNCs who have retained their age long monopolistic advantage. Their comparative technological advantages built over the years make them operate under conditions of reducing cost continually. Scale economies allow them to charge ridiculously low prices to scare away potential entrants. This leaves market forces and the price mechanism at the whims and caprices of the MNCs and nothing more.

Equally, the assumption of perfect availability of information is unrealistic and misleading because globalization is associated with increasing tacitness of vital information, which makes it still possible to 'hide' the uncodified 
aspects of new technologies. As Macdonald (1990:66) rightly puts it, information is an economic good like any other, and yet it is not like any other. When, say, a car is sold the buyer acquires the car and the seller surrenders it. When information is sold the buyer certainly acquires it, but the information is still retained by the seller. Moreover, the transaction itself can be tricky. A potential buyer may examine a car in all the detail he likes before purchase. But a potential purchaser of information may be allowed no such indulgence because close inspection of information becomes the same as acquisition and is likely to obviate the need for the purchase. Since the purchasers of information may never be allowed to know much about what they are buying, the market for information is inherently imperfect.

This does not mean that few information transactions do not take place; obviously vast numbers occur, but it is not quite as other transactions. Competition has increased assess to vital technological information, but growing tacitness of information now makes it more difficult for new entrant to capture and retain new markets. For Sen (1980:134), what is remarkable is the way in which the MNCs have used advanced production techniques in economically backward countries to make huge profits; very often, without making any substantial contribution to the technological capability of those backward economics. In a good many cases, modern technology has sat on these developing countries in much the same way a drop of water sits on a lotus leaf, "no mark anywhere and always ready to roll of."

\section{Skill Intensity And Technology Transfer}

The modern industry is highly specialized and differentiated. It is hard to find a firm that produces an entire machine completely with the major components intact. The parts are produced by different firms which may be scattered across the world, and the production of components and the location of producing firms are differentiated and fragmented. Different competencies, skills, and knowledge are required for the highly specialized operations. Nothing in one operation may allow an expert to be equally competent in even the most related operation. Serious technical limits that exists in the degree to which substitution of factors, and substitution among units of the modern industry can be done have made the neoclassical economic continuous production function largely irrelevant (Saul, 1972:36).

Equally, there is a growing distinction between operational competencies on the job (ability to utilize existing technologies) and innovative competencies (ability to generate new technologies). While the first kind of competency is easier to acquire because it is located alongside the relevant production processes, the second is located elsewhere and difficult to acquire from the production floor. What leaks out to workers from poor countries as new technologies are the operational or technology-using competencies, and very little or incomplete technology-generating competencies.

\section{Policy Imperative For Poor Countries \\ - $\quad$ Accept Globalization as a fact of Human History}

Globalization cannot be wished away. While it is true that the advanced economies have substantial technological advantage, the phenomenal success of several developing economies today point to the fact that poor economies can strategically locate themselves to gain from globalization.

\section{- Poor countries should strive for more interaction between their firms and firms of fast growing countries.}

Access to new knowledge and the various ICT infrastructures should be improved continually. But there is need to strengthen the capacity of the local people to 'distill' knowledge or separate the universal truths and techniques from idiosyncrasies of the Western culture. The curriculum for formal and non-formal education and socio-cultural orientation academic programmes at all levels of formal and non-formal education should implant in people the mindset that questions new and existing knowledge, and reject what is not applicable. Such a re-orientation may be difficult in the short-run; but it remains the most important requirement for nurturing the location relevant industrial culture.

\section{- Continually re-examine the neoclassical economic paradigm}

The assumptions of neoclassical economics are increasingly unrealistic and the mercantilist cultural milieu that justified it is now defunct. The modern industry is completely different from Alfred Marshall's or Adam Smith's producing firm. The invisible hand of Adam Smith or the Market forces of Alfred Marshall have today become the whims and caprices of the MNCs. As Touraine (1988:452) rightly observes:

Development is not continuous evolution, a gradual passage from the particular to the universal. It is the transition from seeing things in terms of continuity which marks the principal break between today's thought and the thought of the previous century.

For instance, it is particularly important to re-examine the association of human well-being maximization with either utility or profit maximization. Economic development of the West has been based on the natural law philosophy that lays emphasis on private poverty, security and liberty as the basis of social order. The emphasis of the natural law philosophy and individualism has helped to destroy the social structure in the West, and the 
moral arithmetic has helped to place material progress in the forefront of all human activities. Material progress has been achieved, but at a great cost. It is evident that there is great psychological and social problem in the West - the high rate of addiction to drugs, suicide, and juvenile delinquency, among others - can be linked to individualism. Rather than generate satisfaction, material progress has resulted in mental confusion. Economic development should, therefore, be promoted in a manner that is in conformity with, or preserve, the other means that are cherished by the society concerned for achieving the social good (Okwuosa, 1976).

\section{- $\quad$ Balance empiricism with economic philosophy and value judgment}

Economics should be given human more touch. Current models sometimes lack social logic and relevance. The notion of the 'economic man' is a mere mercantilist rhetoric, and there are several aspects of human development that quantitative techniques cannot measure. It should also be noted that there are no universal truths, and each society can identify its economic goals in line with its cultural and historical specificities.

\section{- Invest explicitly in building technological capabilities}

Poor countries should focus more resources to building capacity for innovativeness, adaptation of new technologies, and distilling information. The platform for distilling knowledge should be the minds of the people, particularly the educated ones. The distilling process should provide the momentum required for the formation of a scientific culture and an enterprising mentality in the society. Poverty and wealth, weakness and strength, or faith and fear are all generated and held up in the mind. The mind of inferiority, fear, and poverty should be transformed. This would require mind engineering, liberal and affordable education, and the conscious development of the class of scientific thinkers. Tertiary education is clearly central to this process.

\section{- Consciously leapfrog dirty technologies}

Poor countries should strive to innovate, adapt, and adopt technologies that are environmentally sustainable, and less wasteful. There can be no sustainability without discipline; production and consumption of goods and services that are not useful should be outlawed. It is equally necessary to leapfrog the 'dirty technologies' and strive to be at the forefront of modern research. The dominant thinking in development studies that poor countries should start with light industries, and progress gradually to medium and then heavy industries has not helped any country to develop. No country can develop by trying to 'catch up' with the advanced economies, rather many of today's fast moving economies developed sectors and industries 'leapfrogged' by developing all sectors simultaneously.

\section{- $\quad$ Check Excessive Export Bias And Import Dependence}

Bhaduri (2000) rightly observes that global balance would be achieved when nation-states define practicable economic roles for themselves in the current setting. Nation-states can shift the balance globally, by relying more on the internal markets and less on the external markets. This would be quite useful for both the rich and the poor nations because the conflictive economic nationalism, which breeds the major ills of globalization, would be minimized.

[1.] Bhaduri, A. (2000) Nationalism and Economic Policy in the Era of Globalization UNU/WIDER Working Paper 188(July).

[2.] Bloomfield, A. I. (1978) The Impact of Growth and Technology on Trade in Nineteenth Century British Thought History of Political Economy 10 (4) 608-635.Essia, U. (2004) Industrialization and Technological Progress: Comparative Developments in East Asia and Sub-Saharan Africa. In I. Garba, F. Egwaikhide \& A. Adenikinju (Eds.). Leading Issues in Macroeconomic Management and Development The Nigerian Economic Society: Ibadan (June) 287-302.Garba, A. (2003) The Past, Present and Possible Futures of Africa In I. Garba, F. Egwaikhide \& A. Adenikinju (Eds.). Leading Issues in Macroeconomic Management and Development The Nigerian Economic Society: Ibadan (June) I-LV.

[3.] Macdonald, S. (1990) Technology and the Tyranny of Export Controls: Whispers Who Dares Macmillan: London.

[4.] Mahler, V. A. (2002) Economic Globalization, Domestic Politics and Income Inequality in the Developed Countries. Paper Presented at the 2002 Annual Meeting of the Southern Political Science Association. Savannah, Georgia. November, 7-9.

[5.] Okwuosa, E. (1976) New Directions for Economic Development in Africa African Books: London.

[6.] Onimode, B. (2000) Africa in the World of the $21^{\text {st }}$ Century Oxford University Press: New York.

[7.] Ploeg, F.V. D. (1994. Growth, Deficits, and Research and Development in the Global Economy in Fredrick V.D. Ploeg and P.Tang (Eds). The HandBook of International Macroeconomics Blackwell: Oxford Ch. 16, 535-577.

[8.] Saul, S. B. (1972) The Nature and Diffusion of Technology in A.J. Young (Ed). Economic Development in the Long Run George Allen \& Unwin: London 36-61.

[9.] Sen, A. (1980) Labour and Technology in J.Cody. H. Hughes \& D. Wall (Eds). Policies for Industrial Progress in Developing Countries. The World Bank 121-158.

[10.] Touraine, A. (1988) Modernity and Cultural Specificities International Social Science Journal XL (4) 444-457.

[11.] Toyo, E. (2001) Delusions of a Popular Pardigm Essays on Alternative Path to Economic Development The Nigerian Economic Society. 